\title{
O TRABALHO DE QUEM ENSINA: SUPORTE SOCIAL, SUPORTE ORGANIZACIONAL E COMPROMETIMENTO
}

THE WORK OF THOSE WHO TEACH: SOCIAL SUPPORT, ORGANIZATIONAL SUPPORT AND COMMITMENT

EL TRABAJO DE QUIEN ENSEÑA: SOPORTE SOCIAL, SOPORTE ORGANIZACIONAL Y COMPROMISO

\author{
Simone Alves Pacheco de Campos \\ Mestre \\ Universidade Federal de Santa Maria \\ simoneapcampos@gmail.com
}

Vania de Fátima Barros Estivalete

Doutora

Universidade Federal de Santa Maria

vaniaestivalete@ufsm.br

Submetido em: 29/10/2011

Aprovado em: 05/09/2012

\section{RESUMO}

Este estudo teve como objetivo identificar as relações entre o suporte social no trabalho, o suporte organizacional e o comprometimento organizacional, considerando a realidade vivenciada por professores da rede municipal de ensino. Para tanto, realizou-se uma survey com 336 professores. Em relação ao suporte social no trabalho, os resultados sinalizaram para elevada valorização do suporte emocional e informacional e menor valorização de suporte instrumental. Considerando o suporte organizacional, os professores manifestaram elevada percepção. Em relação ao comprometimento organizacional, os resultados revelam maior valorização da base obrigação pelo desempenho. Levando-se em consideração as relações entre os construtos, obtiveram-se elevadas relações entre as bases afiliativa e afetiva do comprometimento organizacional e o suporte social emocional; entre as bases afiliativa e obrigação em permanecer do comprometimento organizacional e a percepção de suporte organizacional; e entre o suporte social emocional e instrumental e a percepção de suporte organizacional.

PALAVRAS-CHAVE: Comprometimento Organizacional. Suporte Social no Trabalho. Suporte Organizacional.

\section{ABSTRACT}

This study aims to identify the relationship between social support at work, organizational support, and organizational commitment, considering the reality of teachers of the municipal education network. To this end, a survey was carried out involving 336 municipal teachers. In relation to social support at work, the results indicated high values for emotional and informational support, and lower values for instrumental support. In relation to organizational support, the teachers attributed high values to this aspect. For organizational commitment, the results show higher values for the Performance Obligation Base. Taking into consideration the relationships between the constructs, high ratios were obtained between the Affiliate and Affective bases of organizational commitment and emotional social support; between the obligation 
to Remain and Affiliative bases of organizational commitment and organizational support; and between emotional and instrumental social support and organizational support.

KEYWORDS: Organizational commitment. Social support at work. Organizational support.

\section{RESUMEN}

Este estudio tuvo como objetivo identificar las relaciones entre el soporte social en el trabajo, el soporte organizacional y el compromiso organizacional, considerando la realidad vivenciada por profesores de la red municipal de educación. Para ello se realizó una survey con 336 profesores. En relación al soporte social en el trabajo, los resultados indicaron una elevada valorización del soporte emocional e informacional y una menor valorización del soporte instrumental. Considerando el soporte organizacional, los profesores manifestaron elevada percepción. En relación al compromiso organizacional, los resultados revelan mayor valorización de la base obligación por el desempeño. Tomando en cuenta las relaciones entre los constructos, se obtuvieron elevadas relaciones entre las bases afiliativa y afectiva del compromiso organizacional y el soporte social emocional; entre las bases afiliativa y obligación en permanecer del compromiso organizacional y la percepción de soporte organizacional; y entre el soporte social emocional e instrumental y la percepción de soporte organizacional.

PALABRAS CLAVE: Compromiso Organizacional. Soporte Social en el Trabajo. Soporte Organizacional.

\section{INTRODUÇÃO}

A educação básica desempenha um papel central no desenvolvimento de indivíduos compreendidos como cidadãos plenos e ativos na sociedade. Devido à sua relevância central, os debates acerca da qualidade do ensino têm sido constantes, principalmente no que concerne ao ensino público, oferecido pelo Estado em suas esferas federais, estaduais e municipais. No centro destes debates, emergem a importância e o papel desempenhado pelos professores, os quais ainda convivem com problemas relacionados às condições de trabalho. Esta categoria, conforme enfatizam Reis et al. (2005), é uma das mais expostas a ambientes conflituosos e de alta exigência de trabalho, tais como tarefas extraclasses, reuniões e atividades adicionais, problemas com alunos, pressão do tempo, dentre outros. Estes fatores acabaram por fazer com que a docência fosse considerada, atualmente, como uma das profissões mais estressantes (REIS et al., 2005).

Dentre os fatores que protegem e amenizam os aspectos maléficos do stress e da elevada carga de trabalho, o suporte social e organizacional desempenha um papel central. A percepção de suporte no trabalho caracteriza-se como um significativo aspecto psicológico presente nas relações de trabalho (BERTHELSEN; HJALMERS; SODERFELDT, 2008), podendo impactar diretamente na relação entre o indivíduo e a organização (WIESENFELD; RAGHURAM; GARUD, 2001). No que tange ao contexto do trabalho, o suporte no trabalho é entendido, para fins deste estudo, como o apoio disponibilizado ao indivíduo no trabalho, sendo caracterizado como a crença do funcionário de que a organização fornece-Ihe suporte material, instrumental, emocional e organizacional (GOMIDE JUNIOR; GUIMARÃES; DAMÁSIO, 2008).

Da mesma forma que o suporte social, o suporte organizacional também se encontra relacionado às melhorias na saúde física e mental dos indivíduos, na sua satisfação, no bem-estar, no desempenho nas tarefas e no comprometimento organizacional (PADOVAN, 2005), estando relacionado com a percepção que o indivíduo tem do quanto a organização valoriza as suas contribuições e cuida do seu bem-estar (EISENBERGER et al.1986). Os estudos em torno desta temática sinalizam para a grande importância do suporte organizacional no bem-estar e a qualidade de vida dos indivíduos (EDWARDS; PECCEI, 2010), contribuindo também com melhores resultados para as organizações, como aumento do comprometimento organizacional (RHOADES; EISENBERGHER, 2002). Este, por sua vez, influencia fortemente a disposição dos docentes para se engajarem em atividades cooperativas, reflexivas 
e críticas, sendo também fundamental no sentido de motivar os professores a modificar as suas práticas para atuarem frente às complexas demandas educacionais da atualidade.

Diante do exposto, emerge o seguinte questionamento que serviu como inspiração para o presente estudo: De que forma o suporte social no trabalho e o suporte organizacional relacionamse com o comprometimento organizacional, segundo a percepção de professores da rede municipal de ensino? Visando responder ao questionamento de pesquisa, foram traçados os seguintes objetivos: (i) identificar a percepção dos professores acerca do suporte social no trabalho; (ii) avaliar a percepção dos pesquisados acerca do suporte organizacional; (iii) analisar as bases do comprometimento organizacional mais valorizadas na percepção dos professores; e (iv) estabelecer relações entre os construtos.

Este estudo justifica-se por sua relevância tanto teórica quanto prática. Evidencia-se uma lacuna na literatura no que diz respeito ao estudo do suporte social no trabalho, visto que tais estudos emergiram no campo disciplinar da psicologia e a sua apreensão no campo da administração ainda é recente. Apesar de haver inúmeros estudos que analisam a relação entre o comprometimento organizacional e o suporte organizacional (RHOADES; EISENBERGER, 2002; PANACCIO; VANDERBERGHE, 2009), a relação deste construto com o suporte social no trabalho ainda não foi devidamente explorada, o que revela uma carência de estudos nesse sentido. Em segundo lugar, o estudo justifica-se pela sua contribuição prática, pois, a partir do reconhecimento por parte da organização escolar, da percepção dos docentes sobre o suporte social no trabalho e organizacional, bem como da natureza do comprometimento dos mesmos, o estudo pode auxiliar no desenvolvimento de políticas e práticas de gestão de pessoas, visando tornar o ambiente de trabalho mais agradável por meio do aumento do apoio social e organizacional. Neste sentido, o presente estudo fornecerá resultados importantes para que as organizações escolares possam refletir sobre as suas políticas e práticas de gestão de pessoas, redirecionando os seus esforços para a criação e a manutenção de um ambiente de trabalho que favoreça o comprometimento dos seus professores.

O estudo encontra-se estruturado em mais sete seções, além da introdução. Na seção dois, três e quatro aborda-se a fundamentação teórica utilizada. Na seção cinco, apresenta-se a arquitetura metodológica para operacionalizar o estudo. Na seção seis, são apresentados os resultados, alinhados com os objetivos propostos. Na sexta seção, são expostas as considerações finais; e, por fim, as referências bibliográficas utilizadas.

\section{SUPORTE SOCIAL: COMPREENDENDO A ORIGEM DO SUPORTE NO TRABALHO}

De acordo com Cobb (1976), o suporte social pode ser definido como as informações possuídas pelo indivíduo, as quais o fazem acreditar que é cuidado, querido, amado, estimado e tido como membro de uma rede com obrigações mútuas. Rodriguez e Cohen (1998) afirmam que o tema, frequentemente, é abordado como os processos pelos quais os indivíduos gerenciam recursos psicológicos e materiais disponíveis das suas redes sociais, a fim de aumentar as suas estratégias de resposta a eventos que ocasionam stress, atender as suas necessidades sociais e atingir os seus objetivos.

A temática tem ganhado espaço também no contexto organizacional, tendo em vista que o suporte social configura-se como um aspecto psicológico significativo do ambiente de trabalho, bem como um mecanismo de apoio à realização no trabalho (BERTHELSEN; HJAMELRS; SODERFELDT, 2008). Os estudos empíricos realizados sobre o tema têm demonstrado que o construto apresenta uma relação positiva com a saúde (VÄÄNÄNEN et al., 2003), o bem-estar, a satisfação no trabalho e o comprometimento organizacional (PAPPAS, 2007).

No contexto do trabalho, o suporte social pode ser entendido como o grau com que os indivíduos percebem que possuem relações sociais positivas com os outros (WIESENFELD; RAGHURAM; GARUD, 2001). Para Gomide Junior, Guimarães e Damásio (2008), refere-se à crença global, por parte dos funcionários, de que a organização da qual fazem parte oferece os três tipos de suporte social (emocional, instrumental e informacional), os quais são necessários à realização do trabalho. A literatura acerca do suporte social identifica diferentes dimensões em relação à percepção de suporte social, as quais estão relacionadas aos distintos tipos de apoio que alguém pode receber de 
sua rede social, sendo que os mais amplamente estudados dizem respeito às dimensões emocional, instrumental e informacional (RODRIGUEZ; COHEN, 1998).

O suporte social informacional, de acordo com Cohen (2004), envolve o fornecimento de informações relevantes, destinadas a auxiliar o indivíduo a lidar com as dificuldades, materializandose em forma de conselhos ou orientações para lidar com os seus problemas pessoais. Em conformidade com Rodriguez e Cohen (1998), este tipo de suporte, geralmente, traduz-se sob a forma de conselhos e orientações, com o objetivo de auxiliar a resolução de problemas. A percepção de suporte informacional, de acordo com Gomide Junior, Guimarães e Damásio (2008), refere-se à crença, por parte do funcionário, que a organização possui uma rede de comunicações comum por meio da qual são veiculadas informações precisas e confiáveis.

O suporte social emocional, por outro lado, relaciona-se às expressões de empatia, carinho e confiança (COHEN, 2004). O suporte social emocional pode vir de amigos íntimos, familiares ou colegas de trabalho (PADOVAN, 2005). Hogan, Linden e Najarian (2002) afirmam que este tipo de suporte envolve a comunicação verbal e não verbal, de carinho e preocupação, auxiliando a reduzir a angústia e permitindo a expressão de sentimentos. A percepção de suporte emocional no trabalho, para Gomide Junior, Guimarães e Damásio (2008), é concernente às crenças dos funcionários de que, na organização para qual trabalham, existem pessoas em quem se pode confiar, que se mostram preocupadas umas com as outras, que se valorizam e se gostam.

O suporte social instrumental, no entendimento de Cohen (2004), refere-se ao fornecimento de auxílio material (assistência financeira ou ajuda nas tarefas diárias). Hogan, Linden e Najarian (2002) enfatizam que, por meio do fornecimento de bens materiais, este tipo de suporte visa diminuir os sentimentos de perda de controle. Esta percepção associa-se à crença do indivíduo de que a empresa fornece insumos materiais, financeiros, técnicos e gerenciais necessários à realização de suas tarefas (GOMIDE JUNIOR; GUIMARÃES; DAMÁSIO, 2008).

Diante do exposto, tem-se claro que o suporte social configura-se como um importante aspecto psicológico do ambiente de trabalho, especialmente no que diz respeito à rede de relacionamentos do indivíduo. O apoio social está intimamente vinculado ao conceito de rede social, os laços que o indivíduo mantém com família, amigos, colegas de trabalho, os quais possuem determinada importância para o mesmo (RAKESH, 2012). Aqui, o foco de análise reside no apoio potencial dos relacionamentos do indivíduo. Contudo, ao discutir o contexto do trabalho, o foco de análise deve ser ampliado para incluir aspectos referentes à organização e à forma como esta interage com os indivíduos. Assim, além do suporte social, convém refletir acerca do papel do suporte organizacional, haja vista que este também se encontra relacionado às melhorias na saúde física e mental dos indivíduos, na sua satisfação, no bem-estar, no desempenho nas tarefas e no comprometimento organizacional, bem como nas suas atitudes e nos comportamentos no local de trabalho (PADOVAN, 2005), uma vez que reflete a forma como os funcionários percebem o tratamento recebido por parte da organização. Dessa forma, a próxima seção tratará de aspectos relacionados à percepção de suporte organizacional.

\section{SUPORTE ORGANIZACIONAL: BASE DA RELAÇÃO DE CONFIANÇA ENTRE COLABORADORES E ORGANIZAÇÕES}

Nota-se que, recentemente, organizações preocupadas em proporcionar melhores condições de trabalho aos funcionários buscaram soluções no sentido de oferecer-lhes um melhor ambiente (PADOVAN, 2005). Tais melhorias podem ser entendidas em termos de oferecimento de suporte organizacional, uma vez que este conceito associa-se às ações da organização no sentido de desenvolver seus funcionários, prover recursos, garantir autonomia, visibilidade e reconhecimento (ASELAGE; EISENBERGER, 2003).

De acordo com o entendimento de Eisenberger et al. (1986), a percepção de suporte organizacional diz respeito à crença do funcionário acerca da extensão em que a organização valoriza as suas contribuições e cuida de seu bem-estar. Assim compreendida, a percepção de suporte organizacional constitui a base da relação de confiança entre funcionários e organização, uma vez que a organização perceberá e recompensará pelos esforços extras realizados pelos indivíduos (EISENBERGER; FASOLO; DAVIS-LAMASTRO, 1990). 
Para a compreensão deste conceito e de sua importância, faz-se necessário, todavia, ampliar o entendimento acerca dos mecanismos de troca social e de reciprocidade que ocorrem entre indivíduos e organizações, os quais estabelecem e sustentam os vínculos entre os mesmos. Nesse sentido, o conceito de suporte organizacional encontra-se alicerçado em duas vertentes teóricas: a teoria das trocas sociais e a teoria da norma da reciprocidade (ASELAGE; EISENBERGER, 2003; WAYNE et al. 2002;).

A teoria da troca social, concebida por Blau (1986), explica a motivação existente por trás das atitudes e dos comportamentos adotados pelos indivíduos. O referido autor assinala que as trocas sociais acontecem unicamente com base na confiança e na boa fé entre as partes, envolvendo a oferta de favores, os quais criam obrigações futuras (SIQUEIRA; GOMIDE JUNIOR, 2004). Wayne et al. (2002) enfatizam que a aplicação destes pressupostos em contextos organizacionais ocorre devido ao fato de fornecer uma base para compreensão do papel que as organizações e os gestores exercem na criação de sentimentos de obrigação nos funcionários, bem como comportamentos pró-organizacionais.

Acrescenta-se, ademais, a contribuição de Gouldner (1964) acerca do princípio de reciprocidade. Esta autora menciona que as relações sociais são regidas por um princípio moral, aceito universalmente, o qual define a obrigação de retribuir favores recebidos. Para tanto, sustenta a sua abordagem em duas exigências: (i) deve-se ajudar a quem nos ajuda e, (ii) não se deve prejudicar quem nos beneficia.

Conforme Allen et al. (2008), a percepção de suporte organizacional relaciona-se à avaliação dos funcionários acerca de se e em que medida a organização reconhecerá e premiará o seu esforço, oferecerá apoio às suas necessidades socioemocionais e ajudá-lo-á em seus pedidos. Estes mesmos autores mencionam que um dos fatores importantes relacionados ao suporte organizacional, trata-se da necessidade de se ter um trabalho desafiador e uma carga de trabalho gerenciável, bem como as oportunidades de orientações de carreira.

A fim de avaliar a percepção dos funcionários acerca do apoio fornecido pela organização, Eisenberger et al. (1986) criaram um instrumento de mensuração: a Escala de Percepção de Suporte Organizacional (EPSO). Esta escala consta de 36 afirmativas referentes a possíveis comportamentos que organizações dispensam a seus funcionários, assim como ações destas que resultariam em benefícios ou prejuízos na percepção dos indivíduos (EISENBERGER et al., 1986). A adaptação e a validação da EPSO, no contexto nacional, foram realizadas por Siqueira (2008), sendo construídas duas escalas provenientes da original: uma versão completa e outra reduzida.

Os estudos em torno desta temática sinalizam para a grande importância do suporte organizacional no bem-estar e na qualidade de vida dos indivíduos (EDWARDS; PECCEI, 2010), contribuindo também com melhores resultados para as organizações, como o aumento do comprometimento organizacional (RHOADES; EISENBERGHER, 2002), uma vez que a percepção de suporte organizacional referese à crença dos funcionários de que a organização está disposta a recompensá-los pelo esforço, o que provocaria uma sensação de obrigação de reciprocidade da parte dos mesmos, levando ao aumento do comprometimento organizacional e, de forma semelhante, à tendência de expressar comportamentos que beneficiem a organização (VANDENBERGHE, BENTEIN; STINGLHAMBER, 2004; LAVELLE; RUPP; BROCKNER, 2007; PANACCIO; VANDERBERGHE, 2009).

\section{COMPROMETIMENTO ORGANIZACIONAL: CONCEITOS E PRINCIPAIS VERTENTES TEÓRICAS}

Ao longo da vida, os indivíduos desenvolvem diferentes vínculos com indivíduos, grupos e instituições (SIQUEIRA; GOMIDE JUNIOR, 2004), os quais determinam a natureza das relações que se estabelecem. Estes vínculos podem ser compreendidos por meio do comprometimento do indivíduo com as relações que institui, seja no trabalho ou em sua vida pessoal. Considerando a esfera organizacional, o entendimento sobre comprometimento torna-se fundamental, à medida que, por meio dele, é possível conhecer a relação de compromisso existente entre os indivíduos e a organização.

Medeiros et al. (2003) subilnham que é consenso na literatura atual que o comprometimento possui múltiplos focos e bases. Becker (1992) propõe que os focos do comprometimento sejam entendidos como os seus alvos (a organização, a profissão, o grupo, o sindicato, dentre outros), enquanto que as bases são as naturezas ou os motivos que levam o indivíduo a comprometer-se. 
Ao tratar esta temática, a maioria dos estudos baseia-se no modelo tridimensional de Meyer e Allen (1991), sendo considerado o modelo de maior aceitação no meio acadêmico (MEDEIROS et al. 2005). Meyer e Allen (1991) tratam o comprometimento como um construto multidmensional, que exerce influência na decisão de permanecer na organização, estando relacionada aos sentimentos de obrigação, afeto e necessidade, os quais podem ocorrer em um mesmo indivíduo. Segundo este enfoque, o comprometimento Afetivo reflete o desejo que o indivíduo tem de se manter como membro de uma organização em particular (MEYER; ALLEN, 1991). O comprometimento Instrumental, segundo a ótica de Meyer e Allen (1991), reflete a necessidade do funcionário permanecer na empresa. Por fim, o componente Normativo reflete a crença do funcionário de que há uma obrigação, ou dever moral, em continuar trabalhando na organização (MEYER; ALLEN, 1991).

No contexto brasileiro, destaca-se a proposta de Medeiros et al. (2005). Para estes autores, o comprometimento organizacional é um construto multidimensional em relação às suas bases, apresentando, dessa forma, sete componentes para o comprometimento organizacional: Afetivo, Escassez de Alternativas, Falta de Recompensas e Oportunidades, Obrigação em Permanecer, Obrigação pelo Desempenho, Afiliativo e Linha Consistente de Atividade. O modelo desenvolvido por Medeiros et al. (2005) apresenta, como diferencial, o fato de reunir, em uma única abordagem, distintas vertentes teóricas importantes para a compreensão do construto, tanto na literatura nacional quanto internacional, conforme pode ser visualizado na Figura 1 (um).

Figura 1 - Bases do Comprometimento

\begin{tabular}{|c|c|c|}
\hline Afetivo & $\begin{array}{l}\text { Aceitação eintrojeção de valores e objetivos organizacionais } \\
\text { Congruência de valores individuais eorganizacionais } \\
\text { Envolvimento moral } \\
\text { Adesão }\end{array}$ & $\begin{array}{l}\text { Afetivo(Meyer eAllen, 1991; Mowday Portere } \\
\text { Steers, 1982); Congruência devalores (Kelman, } \\
\text { 1958); Introjeção(Gouldner, 1960); Envolvimento } \\
\text { moral(Etzioni; 1982) }\end{array}$ \\
\hline Afiliativo & $\begin{array}{l}\text { Sentimentodefazer parte } \\
\text { Identificação, desejo deafiliação } \\
\text { Integração no grupo } \\
\text { Vinculoàs relações sociais }\end{array}$ & $\begin{array}{l}\text { Identificação(Kelman, 1958); Integração } \\
\text { (Gouldner, 1960); Identificação(Becker, 1992); } \\
\text { Coesão(Kanter, (1968); Afiliativa(Medeiros e } \\
\text { Enders, 1999) }\end{array}$ \\
\hline $\begin{array}{l}\text { Escassez de } \\
\text { Alternativas }\end{array}$ & $\begin{array}{l}\text { Poucas alternativas fora da organização } \\
\text { Custos emdeixar a organização } \\
\text { Permanênciapornecessidade }\end{array}$ & Continuação-Meyer e Allen (1991) \\
\hline $\begin{array}{l}\text { Falta } \\
\text { Recompensas } \\
\text { Oportunidade }\end{array}$ & $\begin{array}{l}\text { Relações de troca, envolvimentocalculativo } \\
\text { Oportunidades para alcance deexpectativas } \\
\text { Atitudesecomportamentosparaobterresultados específicos }\end{array}$ & $\begin{array}{l}\text { Envolvimento calculativo (Etzioni); Oportunidade } \\
\text { ( Thévenet); Recompensas (Becker, 1992) }\end{array}$ \\
\hline $\begin{array}{l}\text { Linha } \\
\text { Consistente } \\
\text { Atividade }\end{array}$ & $\begin{array}{l}\text { Sidebets, custos e beneficios associados a sua saída } \\
\text { Engajamentoemlinhas consistentes deatividades } \\
\text { Beneficios adquiridos x investimentos realizados }\end{array}$ & $\begin{array}{l}\text { Trocas Laterais (Becker, 1960); (Hrebiniacke } \\
\text { Alluto,1972) }\end{array}$ \\
\hline $\begin{array}{l}\text { Obrigação } \\
\text { Permanecer }\end{array}$ & $\begin{array}{l}\text { Obrigação empermanecer na organização } \\
\text { Sentimentode obrigação } \\
\text { Culpa por deixar }\end{array}$ & Normativo(Meyer eAllen, 1991) \\
\hline $\begin{array}{l}\text { Obrigação } \\
\text { Desempenho }\end{array}$ & $\begin{array}{l}\text { Obrigação ematingir os objetivos organizacionais } \\
\text { Pressões normativas direcionadas aos objetivos organizacionais } \\
\text { Foco nos controles normativos }\end{array}$ & $\begin{array}{l}\text { Pressões normativas (Wiener,1982; eJaros et. al. } \\
\text { 1993); Controle(Kanter, 1968) }\end{array}$ \\
\hline
\end{tabular}

Fonte: Elaborado com base em Medeiros et al. (2005).

Face ao modelo proposto por Medeiros et al. (2005), e relacionando o mesmo com o modelo tridimensional de Meyer e Allen (1991), tem-se que as bases afetiva e afiliativa referem-se à dimensão afetiva do comprometimento; as bases escassez de alternativas, falta de recompensas e oportunidades e linha consistente de atividades dizem respeito à dimensão instrumental; e as bases obrigação em permanecer e obrigação pelo desempenho, à dimensão normativa (MEDEIROS et al., 2005). 


\section{MÉTODOS E PROCEDIMENTOS}

Visando responder ao problema de pesquisa e atingir os objetivos propostos, realizou-se uma pesquisa descritiva, com adoção do método survey, e de cunho quantitativo. A população alvo constou de professores das escolas urbanas da rede municipal de ensino da cidade de Santa Maria, a qual consta de 1558 docentes. Os instrumentos foram distribuídos a toda a população alvo, obtendo-se um índice de retorno de 25,34\% dos questionários enviados, resultando em 336 pesquisados.

Para o desenvolvimento do estudo, o questionário foi estruturado em torno de três modelos teóricos: Escala de Percepção de Suporte Social no Trabalho (EPSST), de Gomide Junior, Guimarães e Damásio (2008); Escala de Percepção de Suporte Organizacional (EPSO), em sua versão reduzida, criada por Siqueira (2008); e a Escala de Bases do Comprometimento Organizacional (EBACO), desenvolvido por Medeiros et al. (2005). Na Figura 2 (dois), visualizase o desenho conceitual da pesquisa.

No que tange à coleta de dados, primeiramente, foi feito o contato inicial com a Secretaria Municipal de Educação, que autorizou a realização da pesquisa. Após, os questionários foram entregues aos diretores das escolas e, em alguns casos, diretamente para os professores, em horários combinados juntamente com a gestão da escola. Cabe acrescentar que os dados foram coletados entre os meses de setembro e novembro de 2010. Para a análise dos dados, os questionários foram tabulados em uma planilha criada no Microsoft Excel e, posteriormente, transpostos para o software "Statistical Package for the Social Sciences 13.0", através do qual se realizaram as análises estatísticas descritivas, de frequência, análise fatorial e coeficiente de correlação de Pearson, os quais serão tratados na seção dos resultados.

Figura 2 - Modelo de Pesquisa

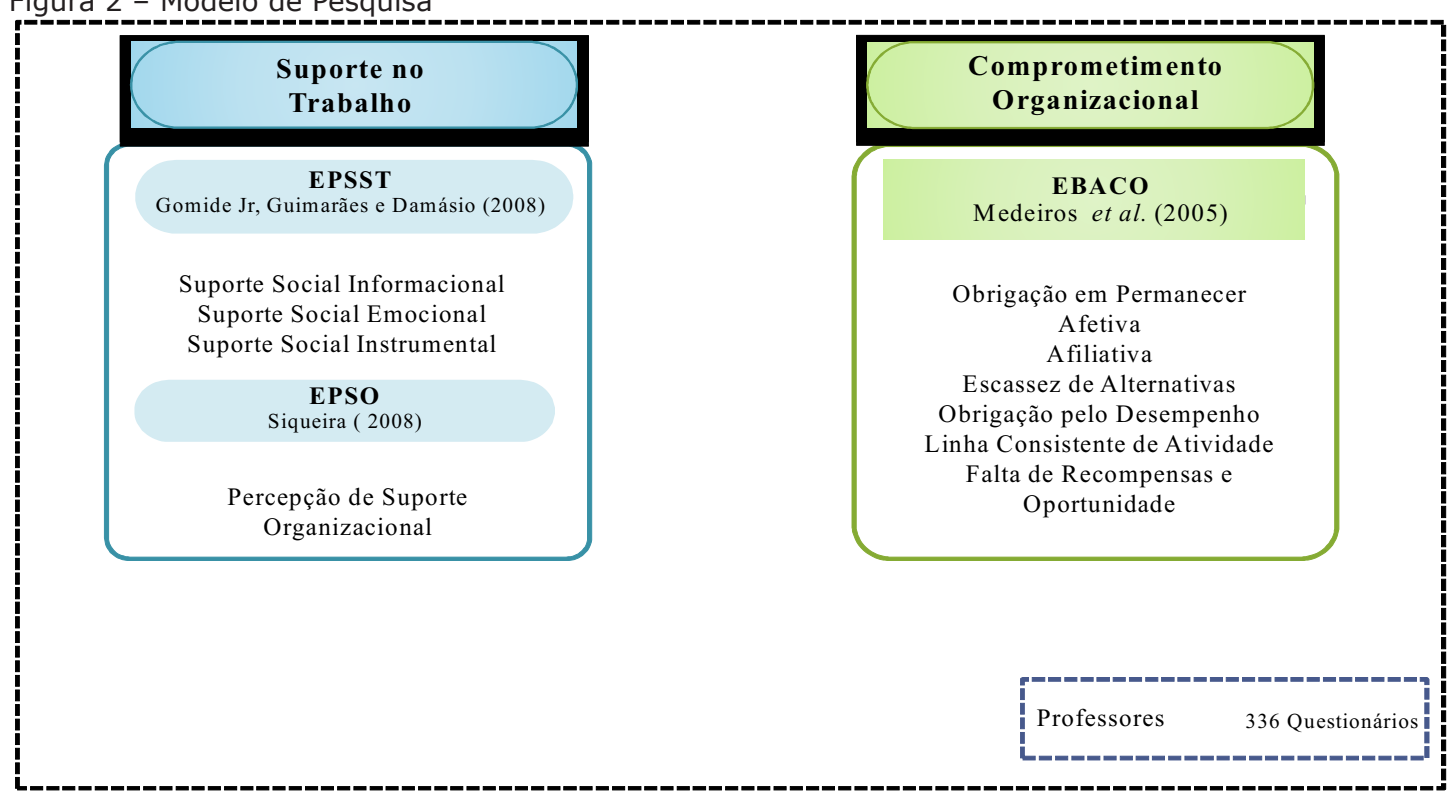

Fonte: Elaborado pelos autores.

\section{ANÁLISE E DISCUSSÃO DOS RESULTADOS}

Nesta seção, serão apresentados os resultados do presente estudo, alinhados com os objetivos propostos na seção introdutória. Anterior à análise e à discussão dos resultados, faz-se necessária a descrição dos respondentes, sintetizada na Figura 3 (três). Compuseram a amostra 336 professores, sendo que, destes, 286 desenvolvem as suas atividades em escolas de ensino fundamental (EMEF), artes e profissional; enquanto que 50 estão atuando em escolas de educação infantil (EMEI). No que diz respeito ao gênero dos professores participantes da pesquisa, quase a totalidade dos respondentes é do sexo feminino, $93 \%$, os quais correspondem a 311 respondentes; enquanto apenas 25 dos respondentes são do sexo masculino, o que equivale a $7 \%$ dos professores pesquisados. 
No que concerne à formação dos profissionais, a maioria $(98,5 \%)$ possui formação superior, e os $1,5 \%$ que não possuem, ainda estão cursando o terceiro grau. Este resultado revela que os profissionais que atuam na educação básica são qualificados, conforme prevê o Plano Nacional de Desenvolvimento da Educação, que pretende qualificar estes profissionais, no mínimo, no ensino superior (BRASIL, 2007). A grande maioria dos professores $(52,8 \%)$ possui formação no curso de Pedagogia, caracterizando um perfil de formação mais genérico. Ao considerar o tempo de atuação na profissão docente, a pesquisa revelou que a maioria dos pesquisados possui mais de 20 anos de profissão $(42,9 \%)$, sendo também expressiva a parcela dos que possuem entre 11 e 20 anos de atuação docente $(31,5 \%)$.

Figura 3 - Perfil da Amostra (Síntese)

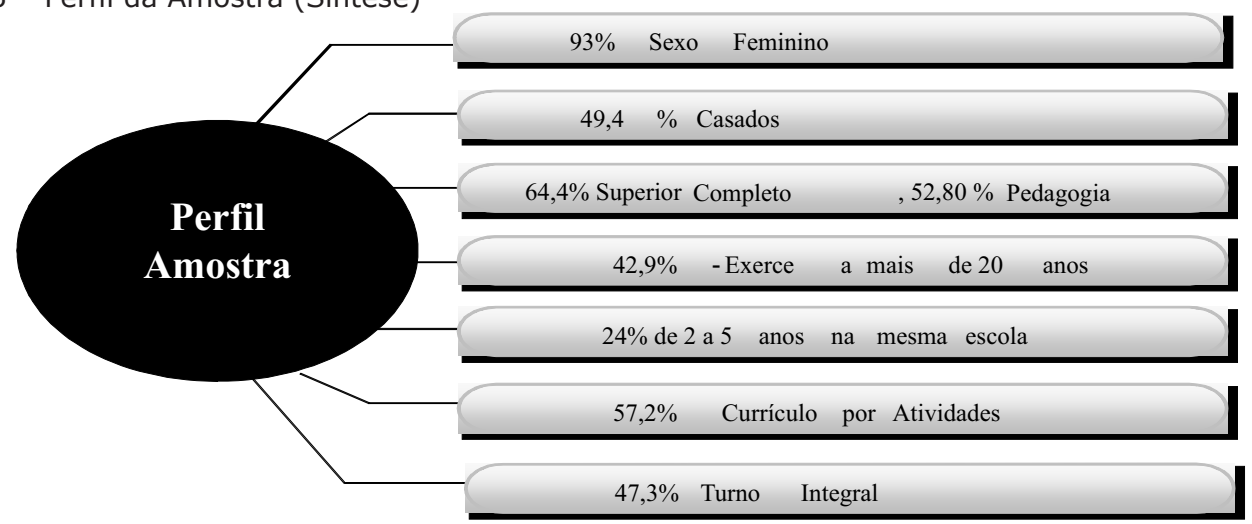

Fonte: Dados da pesquisa.

No que tange ao número de disciplinas ministradas, a maior parte dos professores pesquisados desempenha atividades relacionadas ao ensino de "currículo por atividades"1 (57,2\%). O número expressivo de professores nesta categoria é explicado devido ao fato destas séries serem contempladas por grande parcela das escolas pesquisadas. Cabe salientar o reduzido número de professores que ministram três $(1,1 \%)$ e quatro $(1,4 \%)$ disciplinas. Este dado é positivo, na medida em que os docentes que ministram grande número de disciplinas estão expostos a uma maior carga de trabalho. Em relação à carga horária, os resultados evidenciaram que, em média, os pesquisados possuem uma carga horária de 12 horas semanais. Este resultado mostra-se positivo, tendo em vista que os estudos de Reis et al. (2006) com docentes demonstrou que cargas horárias superiores a 30 horas geram cansaço mental e nervosismo, indicando que o desgaste psíquico pode ser desencadeado ou agravado pela jornada de trabalho elevada.

Além disso, a pesquisa evidenciou que, em média, os pesquisados possuem 24 alunos por turma, estando este fato em consonância com a Lei de Diretrizes e Bases do Brasil (LDB), a qual prevê um número máximo de 25 alunos por turma na educação básica. Nesse sentido, Jackson, Rothmann e Van De Vijver (2006) argumentam que professores que trabalham com turmas grandes apresentam maiores probabilidades de desenvolver problemas relacionados ao stress e à exaustão emocional. Por fim, observou-se que os pesquisados dedicam, em média, nove horas semanais à realização de atividades extraclasse. No entendimento de Codo (1999), o trabalho do professor não se restringe ao exercício de sua função dentro da sala de aula, exige atualização e preparação constantes para ser realizado de modo satisfatório; muitas tarefas são feitas sem a presença dos alunos, fora da sala de aula e, frequentemente, fora da escola, estendendo a jornada de trabalho. Após a identificação do perfil dos pesquisados, as próximas seções expõem a análise dos construtos suporte social no trabalho, o suporte organizacional e o comprometimento organizacional, bem como as relações estabelecidas entre os temas. 


\section{Suporte Social No Trabalho: A Percepção Dos Professores Da Rede Municipal De Ensino}

A fim de compreender como ocorre a percepção acerca do suporte social no trabalho, realizouse, primeiramente, a técnica estatística da análise fatorial por meio do método de componentes principais. Contudo a utilização da análise fatorial requer a realização de testes estatísticos que confirmem a adequação do conjunto de dados à referida técnica. Para tanto, o conjunto de dados foi avaliado de uma forma geral, por meio dos testes de Kaisor-Meyer-Olkin (KMO) e de Esfericidade de Bartlet; e por meio de suas variáveis individualmente, por meio da Medida de Adequação da Amostra. Neste sentido, ambos os testes atestaram a fatorabilidade dos dados, uma vez que foi obtido, para o KMO, igual a 0,857, considerado, por Pestana e Gageiro (2003), como bom para análise fatorial; e, para o teste de Bartlet, o resultado mostrou ser este significativo; em relação à adequação da amostra, os valores excederam aos níveis mínimos aceitáveis, o que indica que o conjunto de dados é adequado à realização da análise fatorial.

Tendo em vista a adequação dos dados, partiu-se para a realização da análise fatorial, por meio do método de componentes principais com normalização Kaiser e rotação varimax. Após, foram testadas as comunalidades, sendo obtidos valores superiores a 0,5, valor considerado, por Pestana e Gageiro (2003), como mínimo. Para a determinação do número de fatores a serem extraídos, foram utilizados, como critérios, percentual de variância explicada, devendo ser igual ou superior a $60 \%$; e autovalores superiores a um (HAIR et al., 2009). Obtiveram-se quatro fatores explicativos da percepção de suporte, os quais explicam conjuntamente $63,4 \%$ da variância, sendo que o primeiro fator concentra aproximadamente $41 \%$ da variância total.

Em relação à confiabilidade, foi calculado o coeficiente Alpha de Cronbach, o qual resultou em índices satisfatórios para três dos quatro fatores. Apenas para um dos fatores não foi obtido um índice de confiabilidade significativo $(0,251)$, uma vez que nem mesmo a exclusão de uma das variáveis que forma este fator proporcionaria acréscimos relevantes no coeficiente, o mesmo foi retirado das análises seguintes. Este fator incluiu questões referentes à percepção de suporte social instrumental, versando sobre a percepção a respeito das recompensas financeiras pelos esforços realizados.

Os resultados indicaram a presença de três fatores explicativos da percepção de suporte social no trabalho. Convém enfatizar que se manteve a mesma estrutura fatorial proposta na escala de Gomide Junior, Guimarães e Damásio (2008), uma vez que não houve modificação na composição dos fatores, em termos de suas variáveis, exceto no que diz respeito às excluídas.

Em relação às cargas fatoriais, a análise dos resultados permite afirmar que foram obtidos valores considerados significativos, visto que são superiores a 0,4 , valor considerado como mínimo por Hair et al. (2009). Além disso, grande parte das cargas fatoriais resultou em valores superiores a 0,7 , o que indica que a variável explica $70 \%$ da variância do fator (HAIR et al., 2009). A fim de analisar a percepção acerca dos tipos de suporte social no trabalho, foram calculados os valores de média, mediana e desvio-padrão, conforme pode ser visto no Quadro 1 (um).

Quadro 1 - Média, Mediana e Desvio Padrão da EPSST

\begin{tabular}{|l|l|l|l|l|}
\hline Fator $\mathbf{1}$ - Suporte Social Informacional no Trabalho a = 0,885 & Carga & Med. & Mdn. & Desv. \\
\hline Variáveis & 0,824 & 3,928 & 4,00 & 0,863 \\
\hline As informações importantes são compartilhadas por todos. & 0,786 & 3,788 & 4,00 & 0,891 \\
\hline As informações importantes são repassadas com agilidade. & 0,779 & 3,918 & 4,00 & 0,836 \\
\hline Os superiores compartilham informações importantes. & 0,734 & 3,702 & 4,00 & 0,942 \\
\hline Há facilidade de acesso às informações importantes. & 0,623 & 4,064 & 4,00 & 0,710 \\
\hline As pessoas são informadas sobre as decisões que envolvem o trabalho & 0,619 & 3,477 & 4,00 & 1,063 \\
\hline Os professores têm os equipamentos necessários para as suas tarefas. & 0,589 & 3,854 & 4,00 & 0,890 \\
\hline As informações circulam claramente entre os setores da escola. & 3,818 & 3,857 & 0,696 \\
\hline TOTAL & & 0,050 \\
\hline
\end{tabular}




\begin{tabular}{|c|c|c|c|c|}
\hline \multicolumn{5}{|l|}{ Fator 2 - Suporte Social Emocional no Trabalho $a=0,869$} \\
\hline Variáveis & Carga & Med. & Mdn. & Desv. \\
\hline As pessoas são amigas umas das outras. & 0,801 & 3,863 & 4,00 & 0,773 \\
\hline Pode-se confiar nas pessoas & 0,763 & 3,595 & 4,00 & 0,909 \\
\hline As pessoas gostam umas das outras. & 0,758 & 3,958 & 4,00 & 0,738 \\
\hline As pessoas podem compartilhar seus problemas pessoais. & 0,726 & 3,784 & 4,00 & 0,855 \\
\hline As pessoas preocupam-se umas com as outras. & 0,582 & 3,725 & 4,00 & 0,878 \\
\hline Pode-se confiar nos superiores & 0,575 & 3,955 & 4,00 & 0,806 \\
\hline \multicolumn{2}{|l|}{ TOTAL } & 3,813 & 4,00 & 0,667 \\
\hline \multicolumn{5}{|l|}{ Fator 3 - Suporte Social Instrumental no Trabalho $a=0,692$} \\
\hline Variáveis & Carga & Méd. & Mdn. & Desv. \\
\hline São pagos salários compatíveis com os esforços dos professores. & 0,724 & 2,120 & 2,00 & 1,180 \\
\hline Há ajuda financeira para que os professores especializem-se. & 0,677 & 2,331 & 2,00 & 1,199 \\
\hline Os equipamentos estão sempre em boas condições de uso. & 0,518 & 3,514 & 4,00 & 1,031 \\
\hline \multicolumn{2}{|l|}{ TOTAL } & 2,669 & 2,667 & 0,793 \\
\hline
\end{tabular}

Fonte: Dados da pesquisa.

Os resultados obtidos demonstram que o tipo de suporte social no trabalho, que obteve maior média $(3,818)$, diz respeito à percepção de suporte social informacional no trabalho. Mesmo este fator tendo obtido escore inferior a quatro, pode-se constatar, por meio da análise da mediana, que os pesquisados tendem a perceber a existência de suporte social informacional, tendo em vista que o valor obtido foi igual a quatro.

Esta percepção encontra-se relacionada, de acordo com o entendimento de Hogan, Linden e Najarian (2002), com a prestação de informações usadas para guiar ou aconselhar os indivíduos. No que tange a este fator, a variável que obteve maior média refere-se "As pessoas são informadas sobre as decisões que envolvem o trabalho que realizam", demonstrando que os professores percebem que as informações pertinentes ao seu trabalho estão disponíveis.

Por outro lado, o fator que obteve menor média concerne à percepção de suporte social instrumental no trabalho. Convém ressaltar que a média atribuída a este fator resultou em valores em torno de 2 (dois), sinalizando para o fato de que os pesquisados demonstram uma carência deste tipo de suporte na escola. O tipo de suporte em questão envolve o fornecimento de materiais, como transporte, dinheiro, assistência física, relacionados ao apoio material disponível (HOGAN; LINDEN; NAJARIAN, 2002). Pertinente ao suporte social instrumental, a menor média foi atribuída à variável "São pagos salários compatíveis com os esforços dos professores", destacando que os pesquisados não concebem que a remuneração recebida é compatível com seus esforços.

Em relação ao desvio-padrão, os resultados permitem inferir que os pesquisados demonstraram maior coerência entre si em relação ao suporte emocional, tendo em vista que este fator obteve menor desvio-padrão. Contudo os pesquisados evidenciam maior divergência em suas respostas em relação à percepção de suporte instrumental. Tendo em vista que as médias obtidas para os tipos de suporte social no trabalho resultaram em valores muito próximos (principalmente no que diz respeito aos tipos informacional e emocional de suporte no trabalho), fez-se necessária a realização do teste t para amostras emparelhadas, conforme exposto no Quadro 2 (dois), com vistas a identificar se há diferença significativa entre as médias para um mesmo respondente (PESTANA; GAGEIRO, 2003). 
Quadro 2 - Teste t entre os tipos de suporte social no trabalho

\begin{tabular}{|l|l|l|l|l|}
\hline \multirow{2}{*}{ Pares } & \multicolumn{2}{|c|}{$\begin{array}{c}\text { Piferenças entre } \\
\text { Pares }\end{array}$} & $t$ & Sig. \\
\cline { 2 - 5 } Suporte social Informacional - Suporte Social Emocional. & 0,03457 & 0,50482 & 1,255 & 0,21 \\
\hline Suporte social Informacional - Suporte Social Instrumental. & 1,81052 & 0,98290 & 33,664 & 0,00 \\
\hline Suporte Social Emocional - Suporte Social Instrumental. & 1,77675 & 0,93622 & 34,683 & 0,00 \\
\hline
\end{tabular}

Fonte: Dados da pesquisa.

Os resultados expostos no Quadro 2 (dois) destacam que não existem diferenças de médias estatisticamente significantes entre os tipos de suporte Informacional e Emocional, visto que o valor de sig foi maior que 0,05. Com base nesse resultado, pode-se inferir que os professores pesquisados percebem de forma semelhante a existência de suporte social emocional e informacional nas escolas.

\section{Suporte Organizacional: Uma relação de troca e reciprocidade entre Professor e Escola}

Para a exploração dos dados referentes à Escala de Percepção de Suporte Organizacional, buscaram-se analisar as estatísticas referentes à adequação dos dados. Primeiramente, foram avaliados os testes de KMO e Bartlet, sendo que os resultados obtidos, em ambos os testes (KMO = 0,858; Bartlet $<0,000$ ), atestaram para a adequação da amostra, de uma maneira geral. Além disso, os resultados obtidos para a Medida de Adequação da amostra também se mostraram adequados aos dados em nível individual.

Após, procedeu-se à realização da análise fatorial, por meio da técnica de componentes principais com normalização Kaizer e rotação varimax. Inicialmente, analisou-se o valor das comunalidades, sendo observado que a variável "Esta escola estaria disposta a ampliar as suas instalações para me ajudar a utilizar melhor minhas habilidades no desempenho do meu trabalho" obteve valor inferior a 0,5 $(0,426)$, sendo necessária a sua exclusão.

Obteve-se um único fator que explica aproximadamente $70 \%$ da variância, valor considerado satisfatório por Hair et al. (2009). Em relação à confiabilidade, o fator obtido demonstrou ser consistente, uma vez que alcançou índice Alpha de Cronbach igual a 0,903, o que revela uma intensidade de associação excelente (HAIR et al., 2009). Os resultados verificados corroboram a literatura acerca da temática, ao caracterizar o suporte organizacional como um construto unidimensional (SIQUEIRA, 2008). Cabe ainda enfatizar que os valores das cargas fatoriais para todas as variáveis resultaram superiores a 0,7, considerado como valor ideal (HAIR et al. 2009). Para fins de análise, calcularam-se as médias, as medianas e o desvio-padrão para as variáveis, bem como para o fator, conforme exposto no Quadro 3 (três).

Quadro 3 - Média, Mediana e Desvio Padrão da EPSO

\begin{tabular}{|l|l|l|l|l|}
\hline Percepção de Suporte Organizacional (P.S.O) a = 0,903 & Carga & Méd. & Mdn. & Desv. \\
\hline Variáveis & 0,918 & 4,139 & 4,00 & 0,720 \\
\hline Esta escola preocupa-se com a minha satisfação no trabalho. & 0,894 & 4,060 & 5,00 & 0,833 \\
\hline Esta escola realmente preocupa-se com o meu bem-estar. & 0,872 & 3,674 & 5,00 & 1,001 \\
\hline Esta escola tenta fazer com que o meu trabalho seja interessante. & 0,842 & 4,081 & 4,00 & 0,881 \\
\hline Esta escola está pronta a ajudar-me quando eu preciso de favor especial. & 0,850 & 4,054 & 4,00 & 0,795 \\
\hline É possível obter ajuda desta escola quando tenho um problema. & 4,070 & 4,00 & $\mathbf{0 , 7 1 1 1}$ \\
\hline TOTAL & & &
\end{tabular}

Fonte: Dados da pesquisa. 
De uma forma geral, pode-se observar, conforme pode ser visualizado no Quadro 3 (três), que os professores pesquisados percebem um alto nível de suporte organizacional, fato evidenciado pela média obtida para o fator $(4,07)$. Este resultado remete à compreensão de que os professores analisam que a escola valoriza as suas contribuições e cuida do seu bem-estar (EISENBERGER et al. 1986).

Em relação à avaliação das variáveis, a maior média obtida $(4,139)$ foi para a variável "Esta escola preocupa-se com a minha satisfação no trabalho". Os resultados sinalizam para o fato de que os pesquisados percebem as iniciativas organizacionais que visam à satisfação no trabalho. De acordo com o entendimento de Aselage e Eisenberger (2003), a percepção de suporte organizacional encontra-se vinculada às iniciativas da organização em desenvolver seus funcionários, prover recursos, trabalhar com mais autonomia, visibilidade e reconhecimento na organização.

Em contrapartida, a questão de menor média $(3,674)$ foi a "Esta escola tenta fazer com que o meu trabalho seja interessante". Este resultado salienta que, na percepção dos pesquisados, existe uma carência em relação às iniciativas direcionadas à criação de um ambiente de trabalho interessante.

Cabe acrescentar a contribuição de Allen et al. (2008), que ressaltam a importância da necessidade de realização de um trabalho desafiador e interessante para a formação da percepção de suporte organizacional. Em relação a este resultado, convém acrescer as ponderações de Somech e Bogler (2002), ao afirmaremm que uma das formas de tornar o trabalho dos professores mais interessante e desafiador é prover meios para que participem ativamente das decisões da escola, sejam elas relacionadas à gestão ou à organização pedagógica.

\section{Comprometimento Organizacional: Compreendendo a Natureza do Vínculo de Professores para com as Escolas}

Para a exploração dos dados referentes à Escala de Bases do Comprometimento Organizacional (EBACO), foi utilizada a técnica estatística da análise fatorial. De início, buscou-se testar a adequação da amostra, tanto em níveis globais (por meio dos testes de KMO e Barltet) quanto em níveis individuais (por meio da Medida de Adequação da Amostra - MASA). Os resultados obtidos nestes testes apontaram a adequação dos dados à análise fatorial, sendo obtido um valor considerado adequado para o teste de $\operatorname{KMO}(0,854)$ e os testes de Bartlet e MASA conferiram índices significantes.

Após verificar a adequação da amostra, prosseguiu-se à identificação das comunalidades. Os resultados apontaram para comunalidades inferiores a 0,5 em duas variáveis: "Se eu não tivesse dado tanto de mim nesta escola, eu poderia considerar trabalhar em outro lugar" $(0,309)$ e para: "Se eu decidisse deixar minha escola agora, minha vida ficaria bastante desestruturada" $(0,406)$, sendo necessária a exclusão das mesmas e a reespecificação do modelo fatorial. Com o novo modelo, foram verificados valores de comunalidades significativos para todas as variáveis, tornando-se viável a extração dos fatores da escala.

A análise fatorial resultou em sete fatores, os quais explicam, conjuntamente, 70,94\% da variância acumulada, o que, conforme Hair et al. (2009), é satisfatório. Para avaliar a confiabilidade dos dados agrupados em fatores, foi calculada a consistência interna por meio do coeficiente Alpha de Cronbach. Em relação aos resultados obtidos para este coeficiente, pode-se observar que, conforme mostra o Quadro 4 (quatro), todos os fatores obtidos apresentam índices de confiabilidade que atestam a consistência interna (HAIR et al., 2005).

Em relação às cargas fatoriais, evidencia-se que todos os valores podem ser considerados significantes, uma vez que possuem valor superior a 0,4 e que, na maioria dos casos, os valores obtidos foram superiores a 0,7, conforme recomendados por Hair et al. (2009). Convém ressaltar que, em relação à estrutura fatorial obtida, manteve-se a mesma estrutura do modelo de Medeiros et al. (2005) e, exceto pelas variáveis excluídas da análise, nenhuma variável sofreu alteração em relação ao seu fator de origem, confirmando a estrutura individual dos fatores. Para fins de análise dos dados, calculou-se a média, a mediana e o desvio-padrão das variáveis e dos fatores, conforme pode ser visualizado no Quadro 4 (quatro). 
Quadro 4 - Comprometimento Organizacional: Média, Mediana e Desvio Padrão

\begin{tabular}{|c|c|c|c|c|}
\hline \multicolumn{5}{|l|}{ Fator 1 Base Obrigação pelo Desempenho (0.Des) $a=0,864$} \\
\hline Variáveis & Carga & Méd. & Mdn. & Desv. \\
\hline O bom professor deve esforçar-se para a escola ter melhores resultados. & 0,820 & 4,608 & 5,00 & 0,547 \\
\hline O professor tem a obrigação de sempre cumprir suas tarefas. & 0,791 & 4,512 & 5,00 & 0,589 \\
\hline Eu tenho obrigação em desempenhar bem minha função escolar. & 0,782 & 4,614 & 5,00 & 0,557 \\
\hline Todo professor deve buscar atingir os objetivos da escola. & 0,597 & 4,325 & 4,00 & 0,687 \\
\hline \multicolumn{2}{|l|}{ Total do Fator } & 4,513 & 4,75 & 0,504 \\
\hline \multicolumn{5}{|l|}{ Fator 2 Base Obrigação em Permanecer (O.Per) a = 0,898 } \\
\hline Variáveis & Carga & Méd. & Mdn. & Desv. \\
\hline $\begin{array}{l}\text { Acredito que não seria certo deixar escola, porque tenho obrigaçäo moral } \\
\text { em permanecer aqui. }\end{array}$ & 0,854 & 3,410 & 4,00 & 1,202 \\
\hline Mesmo se fosse vantagem, sinto que não seria certo deixar a escola. & 0,847 & 3,825 & 4,00 & 1,063 \\
\hline Eu me sentiria culpado se deixasse minha escola agora. & 0,846 & 3,515 & 4,00 & 1,221 \\
\hline $\begin{array}{l}\text { Näo deixaria a escola agora, porque tenho obrigação moral com as } \\
\text { pessoas daqui. }\end{array}$ & 0,779 & 3,816 & 4,00 & 1,067 \\
\hline \multicolumn{2}{|l|}{ Total } & 3,640 & 4,00 & 0,992 \\
\hline \multicolumn{5}{|l|}{ Fator 3 Base Afiliativa (Afi) $a=0,863$} \\
\hline Variáveis & Carga & Méd. & Mdn. & Desv. \\
\hline Sou reconhecido por todos na escola como membro do grupo. & 0,876 & 4,285 & 4,00 & 0,703 \\
\hline $\begin{array}{l}\text { Sinto que meus colegas consideram-me como membro da equipe } \\
\text { trabalho }\end{array}$ & 0,852 & 4,338 & 4,00 & 0,583 \\
\hline Nesta escola, eu sinto que faço parte do grupo. & 0,730 & 4,450 & 4,00 & 0,612 \\
\hline Fazer parte do grupo é o que me leva a lutar por esta escola. & 0,625 & 4,172 & 4,00 & 0,785 \\
\hline \multicolumn{2}{|l|}{ Total } & 4,311 & 4,25 & 0,568 \\
\hline \multicolumn{5}{|l|}{ Fator 4 Base Linha Consistente de Atividade (L.Con) $a=0,752$} \\
\hline Variáveis & Carga & Méd. & Mdn. & Desv. \\
\hline $\begin{array}{l}\text { Na situação atual, ficar na escola é uma necessidade tanto quanto um } \\
\text { desejo. }\end{array}$ & 0,788 & 3,387 & 4,00 & 1,191 \\
\hline Procuro não transgredir as regras, pois, assim, manterei meu emprego. & 0,748 & 2,912 & 3,00 & 1,296 \\
\hline Farei sempre o possível em meu trabalho para manter-me nesta escola. & 0,701 & 3,660 & 4,00 & 1,067 \\
\hline Para conseguir ser recompensado é necessário expressar a atitude certa. & 0,645 & 3,012 & 3,00 & 1,133 \\
\hline \multicolumn{2}{|l|}{ Total } & 3,244 & 3,25 & 0,898 \\
\hline \multicolumn{5}{|l|}{ Fator 5 Base Escassez de Alternativas (Esc.At) a = 0, 824} \\
\hline Variáveis & Carga & Méd. & Mdn. & Desv. \\
\hline $\begin{array}{l}\text { Uma das consequências negativas de deixar a escola seria a escassez de } \\
\text { alternativas imediatas de trabalho. }\end{array}$ & 0,908 & 1,922 & 2,00 & 0,929 \\
\hline Não deixaria este emprego devido à falta de oportunidades. & 0,813 & 1,949 & 2,00 & 0,953 \\
\hline Acho que teria poucas alternativas de emprego se deixasse esta escola. & 0,792 & 1,928 & 2,00 & 0,948 \\
\hline \multicolumn{2}{|l|}{ Total } & 1,948 & 2,00 & 0,837 \\
\hline \multicolumn{5}{|l|}{ Fator 6 Base Afetiva $a=0,810$} \\
\hline Variáveis & Carga & Méd. & Mdn. & Desv. \\
\hline A razão de eu preferir esta escola é por causa de seus valores. & 0,778 & 3,976 & 4,00 & 0,872 \\
\hline Eu identifico-me com a filosofia desta escola. & 0,664 & 4,254 & 4,00 & 0,712 \\
\hline $\begin{array}{l}\text { Desde que me juntei à escola, meus valores e os dela têm se tornado } \\
\text { similares. }\end{array}$ & 0,653 & 4,027 & 4,00 & 0,709 \\
\hline Eu acredito nos valores e objetivos desta escola. & 0,582 & 4,383 & 4,00 & 0,628 \\
\hline \multicolumn{2}{|l|}{ Total } & 4,164 & 4,00 & 0,586 \\
\hline
\end{tabular}


Fator 7 Base Falta de Recompensas e Oportunidades (F.Rec) a = 701

\begin{tabular}{|l|l|l|l|l|}
\hline Variáveis & Carga & Méd. & Mdn. & Desv. \\
\hline Minha visão pessoal sobre a escola é diferente daquele que eu expresso. & 0,852 & 1,671 & 2,00 & 0,831 \\
\hline $\begin{array}{l}\text { Apesar dos esforços que realizei, não vejo oportunidades nesta escola. } \\
\text { A menos que eu seja recompensado de alguma maneira, não vejo razões } \\
\text { para despender esforços extras em benefício desta escola. }\end{array}$ & 0,783 & 1,647 & 1,00 & 0,867 \\
\hline Total & 1,973 & 2,00 & 1,010 \\
\hline
\end{tabular}

Fonte: Dados da pesquisa.

Pode-se observar, por meio dos resultados expostos no Quadro 4 (quatro), que a maior média obtida $(4,513)$ foi para a base obrigação pelo desempenho. Estes resultados indicam a presença de um sentimento de obrigação em atingir os objetivos organizacionais, que retrata a natureza do comprometimento organizacional dos pesquisados. Assim, os resultados obtidos permitem inferir que os professores pesquisados relacionam a sua permanência na escola ao dever de alcançar as metas e os objetivos dela, bem como a busca de melhores resultados para a mesma (MEDEIROS et al., 2005).

Em relação a este fator, a variável que obteve maior média $(4,614)$ foi a "Eu tenho obrigação em desempenhar bem a minha função na escola", reforçando o pressuposto de que a natureza do comprometimento organizacional encontra-se relacionada ao sentimento de que se devem atingir os objetivos da escola. Em relação a esta base, a análise do desvio-padrão permite entender que os respondentes apresentaram maior coerência entre si na avaliação da mesma, uma vez que foi obtido o menor valor de desvio-padrão.

Em contrapartida, a menor média foi atribuída à base falta de recompensas e oportunidades $(1,769)$. Dessa forma, estes achados podem sinalizar para o fato de que os sujeitos pesquisados não acreditam que a sua permanência na escola vincule-se à crença de que seus esforços devem ser recompensados, bem como que deve the oferecer maiores oportunidades (MEDEIROS et al., 2005). Relativo a este fator, a menor média deu-se na questão "Apesar dos esforços que já realizei, não vejo oportunidades para mim nesta escola". Convém ressaltar que a referida base resultou no maior desvio-padrão, tendo sido obtido um valor próximo a um, demonstrando que, nesta base, houve uma maior divergência entre os professores pesquisados, expressando-se ser uma percepção compartilhada por um menor número de pesquisados.

\section{A Relação entre Suporte Social no Trabalho, Suporte Organizacional e Comprometimento Organizacional}

A fim de compreender a relação entre as percepções de suporte social no trabalho, de suporte organizacional e de comprometimento organizacional de professores da rede municipal de ensino, em continuidade, procedeu-se à análise de correlação entre os construtos por meio do cálculo do coeficiente de correlação de Pearson.

Tabela 1 - Matriz de Correlação

\begin{tabular}{l|l|l|l|l|l|l|l|l|l|l|l}
\hline & SSINF & SSEMO & SSINS & O.Des & O.Per & Afil & L.Cons & E.Alte. & Afet & F.Re.Opr & PSO \\
\hline SSINF & 1 &, $682^{* *}$ &, $472^{* *}$ &, $353^{* *}$ &, $210^{* *}$ &, $433^{* *}$ &, $187^{* *}$ &, 059 &, $751^{* *}$ &,$- 118^{*}$ &, $715^{* *}$ \\
\hline SSEMO & & 1 &, $368^{* *}$ &, $325^{* *}$ &, $229^{* *}$ &, $852^{* *}$ &, $118^{*}$ &, 020 &, $706^{* *}$ &,$- 121^{*}$ &, $742^{* *}$ \\
\hline SSINS & & & 1 &, $276^{* *}$ &, $223^{* *}$ &, $288^{* *}$ &, $180^{* *}$ &, $202^{* *}$ &, $297^{* *}$ &, 042 &, $385^{* *}$ \\
\hline O.Des & & & & 1 &, $412^{* *}$ &, $609^{* *}$ &, $349^{* *}$ &,- 025 &, $597^{* *}$ &,$- 136^{*}$ &, $411^{* *}$ \\
\hline O.Per & & & & & 1 &, $341^{* *}$ &, $295^{* *}$ &, 024 &, $449^{* *}$ &,- 029 &, $778^{* *}$ \\
\hline Afil. & & & & & & 1 &, $162^{* *}$ &,- 044 &, $572^{* *}$ &,- 089 &, $703^{* *}$ \\
\hline L.Cons & & & & & & 1 &, $294^{* *}$ &, $242^{* *}$ &, $126^{*}$ &, $170^{* *}$ \\
\hline E.Alte. & & & & & & & & 1 &, 041 &, $325^{* *}$ &, 047 \\
\hline Afet. & & & & & & & & & 1 &,$- 123^{*}$ &, $761^{* *}$ \\
\hline F.Re.Opr & & & & & & & & & & 1 &,- 067 \\
\hline PSO & & & & & & & & & & & 1 \\
\hline
\end{tabular}

*Correlaçáo é significativa ao nivel de 0,05

**Correlação é significativa ao nível de 0,01.

Fonte: Dados da pesquisa. 
Quanto à intensidade das correlações entre os fatores, tem-se que, para valores menores que 0,2 , a correlação é determinada como muito baixa; valores entre 0,2 e 0,39 , a correlação entre os fatores é baixa; valores compreendidos entre 0,4 e 0,69, a correlação entre os fatores é moderada; entre 0,7 e 0,89, as associações são consideradas altas e valores entre 0,9 e 1 indicam associações muito altas (PESTANA; GAGEIRO, 2003).

Considerando o relacionamento entre a percepção de suporte social no trabalho e as bases do comprometimento organizacional, pode-se afirmar que os resultados demonstram existir, na maioria dos casos, correlações baixas. Entretanto os resultados evidenciaram coeficientes de correlação tidos como moderados para as associações entre a percepção de suporte social informacional (SSINF) e a base afiliativa (Afil); e altas entre a base afetiva e as percepções de suporte social informacional (SSINF) e suporte social emocional (SSEMO), e entre a base afiliativa (Afil) e suporte social emocional (SSEMO).

A maior correlação obtida $(0,852)$ deu-se entre a percepção de suporte social emocional (SSEMO) e a base afiliativa (Afil). Este resultado remete à compreensão de que, quanto mais forte a percepção de que há, na escola, pessoas que se preocupam umas com as outras, ajudam-se e gostam-se (GOMIDE JUNIOR; GUIMARÃES; DAMÁSIO, 2008), maior será o sentimento do indivíduo de que a sua permanência na organização relaciona-se ao fato de sentir-se membro do grupo e vinculado emocionalmente às redes sociais existentes.

Os resultados também mostraram existir correlações elevadas entre os tipos informacional (SSINF) e emocional (SSEMO) do suporte social no trabalho e a base Afetiva (Afet) do comprometimento organizacional $(0,751$ e 0,706 , respectivamente). Tais resultados sinalizam que o sentimento, por parte do professor, de identificação com a filosofia, os valores e os objetivos da escola (MEDEIROS et al., 2005) encontra-se associado à percepção de que a mesma o provê de suporte social em nível informacional e emocional. Em relação a estes resultados, convém salientar as ponderações de Jones (2005) que, em seus estudos, observou existir associações moderadas entre o comprometimento afetivo e a percepção de suporte emocional. Além disso, os estudos de Padovan (2005) corroboram os resultados encontrados, uma vez que esta autora também obteve correlações positivas entre o comprometimento afetivo e a percepção de suporte informacional no trabalho.

Por outro lado, a menor correlação deu-se entre a percepção de suporte social emocional (SSEMO) e a base linha consistente de atividade (L.Cons) $(0,118)$ e entre a percepção de suporte social informacional (SSINF) e a base falta de recompensas e oportunidades (F.Re.Opr) $(-0,118)$. Estes resultados sugerem que os professores associam, de maneira muito baixa, a tendência em permanecer na organização devido à percepção de que deixar a escola seria um "alto sacrifício", visto que perderiam benefícios materiais ou psicológicos (MEDEIROS et al. 2005), com a percepção de que possui, na organização, uma rede social que o auxilia com problemas de nível emocional (COHEN, 2004). Ainda se observa que existe correlação baixa e inversa entre a percepção de suporte informacional e a base falta de recompensas e oportunidades, indicando que, quanto maior a percepção acerca do apoio informacional, menor a valorização da base falta de recompensas e oportunidades e vice-versa.

Considerando a forma como a percepção de suporte organizacional relaciona-se com as bases do comprometimento organizacional, os resultados evidenciaram a existência de três correlações elevadas, as quais se deram entre a percepção de suporte organizacional e as bases obrigação em Permanecer (O.Per) $(0,778)$, afiliativa (Afil) $(0,703)$ e afetiva (Afet) $(0,761)$ (PESTANA; GAGEIRO, 2003).

No que tange à relação entre a base obrigação em permanecer (O.Per) e afetiva (Afet) e a percepção de suporte organizacional (PSO), a literatura acerca dos temas confirma os resultados obtidos, tendo em vista que a relação entre o suporte organizacional e o comprometimento afetivo e normativo tem sido alvo de muitos estudos (RHOADES; EISENBERGER; ARMELI, 2001).

Os resultados verificados demonstram, ademais, que, quanto maior a percepção de suporte organizacional, maior será o comprometimento afetivo e relacionado à base obrigação em permanecer, a qual pressupõe um vínculo normativo do professor com a escola. Podem-se explicar tais resultados devido ao fato de que tanto o comprometimento afetivo quanto o normativo constituem-se como formas de reciprocidade para experiências positivas no trabalho, levando ao desenvolvimento de sentimentos de obrigação em retribuir um favor e permanecer na organização (RHOADES; EISENBERGER, 2002). 
Por outro lado, a correlação mais baixa $(0,170)$ residiu entre a base linha consistente de atividade (L.Cons) e a percepção de suporte organizacional (PSO). Este resultado permite concluir que os professores não associam os custos percebidos com a saída da organização, devido aos investimentos realizados na mesma, com a percepção de que a escola valoriza as suas contribuições e cuida do seu bem-estar.

Cabe ainda enfatizar as correlações auferidas entre as percepções de suporte social no trabalho e organizacional. Em relação a estes resultados, observa-se que a maioria dos valores obtidos para os coeficientes de correlação podem ser considerados como elevados, apenas a correlação entre a percepção de suporte social instrumental (SSINS) e a percepção de suporte organizacional (PSO) revela uma intensidade moderada de associação (PESTANA; GAGEIRO, 2003).

Tratando-se destes construtos, a maior associação $(0,742)$ observou-se entre a percepção de suporte social emocional (SSEMO) e a percepção de suporte organizacional (PSO). Este resultado remete à compreensão de que a percepção de suporte organizacional influencia direta e positivamente a percepção de suporte social no trabalho e vice-versa. Assim, quanto maior for a percepção dos professores de que possuem relações sociais positivas com os colegas, através das quais encontram fontes de suporte emocional (GOMIDE JUNIOR; GUIMARÃES; DAMÁSIO, 2008), maior será a percepção de que a escola fornece cuidado, tratamento justo, reconhecimento e valorização aos seus professores.

Cabe destacar que, entre as percepções de suporte social informacional (SSINF) e suporte organizacional (PSO), a correlação obtida $(0,715)$ também é considerada elevada (PESTANA; GAGEIRO, 2003). O resultado mencionado revela que os pesquisados associam a percepção acerca do sistema de comunicação da escola com a provisão de suporte organizacional. A baixa correlação obtida entre a percepção de suporte organizacional (PSO) e o suporte social instrumental no trabalho (SSINS) $(0,385)$ sinaliza que os pesquisados relacionam com intensidade baixa a percepção do compromisso que a organização tem com eles, com a disponibilidade de recursos materiais existentes na escola. Tendo em vista os resultados obtidos, torna-se possível inferir que, considerando a realidade vivenciada por docentes municipais, fatores relacionados ao apoio emocional e informacional no trabalho influenciam positivamente na percepção de compromisso da escola com o bem-estar dos seus professores. A Figura 4 (quatro) mostra a síntese destes resultados.

Figura 4 - Síntese das Relações entre os Construtos

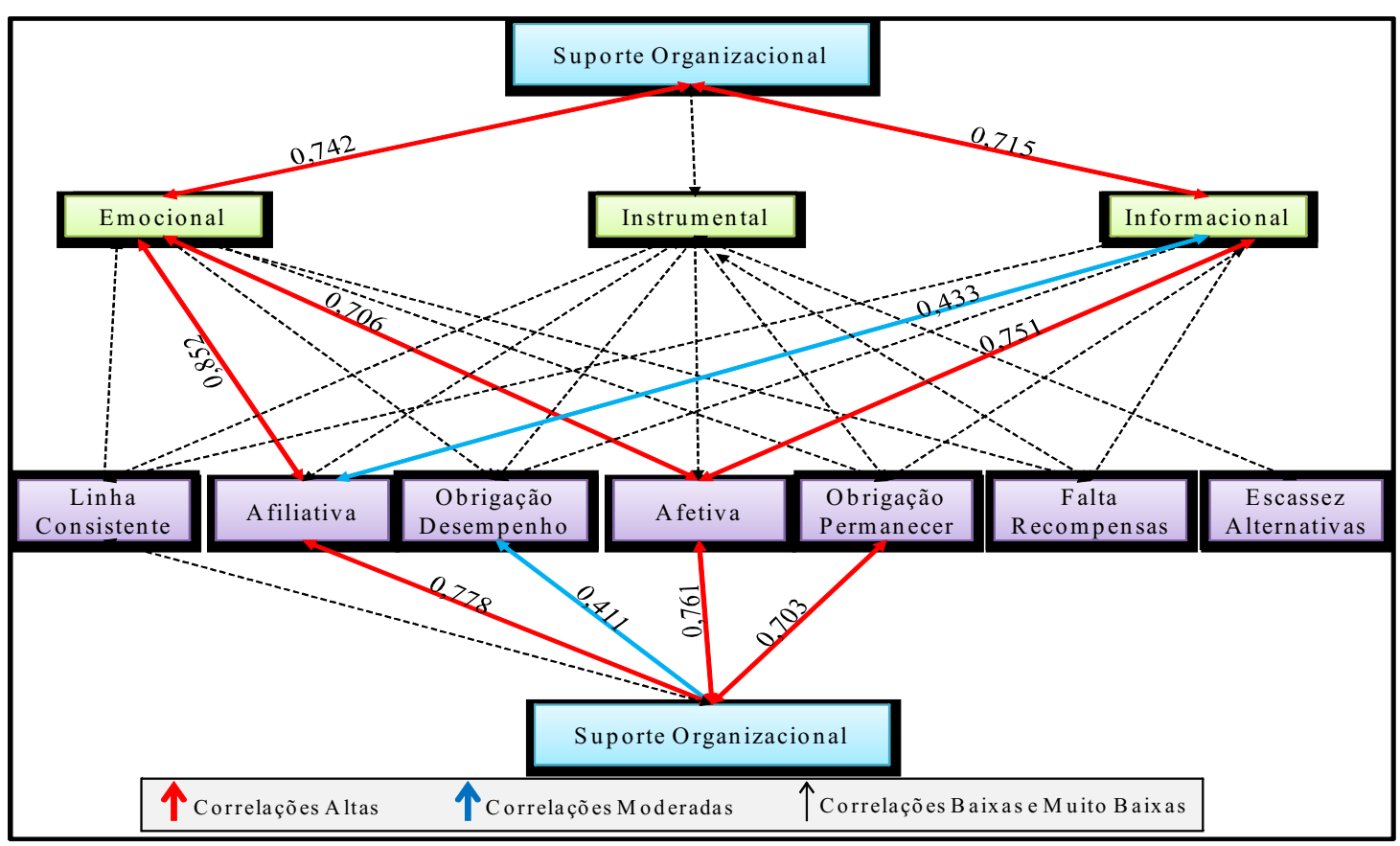

Fonte: Elaborada pelos autores. 


\section{CONSIDERAÇÕES FINAIS}

O cenário atual é marcado pela intensificação do trabalho docente, a ampliação do seu raio de atuação, tendo em vista o acúmulo de atividades, o que, consequentemente, ocasiona maiores desgastes e insatisfação por parte dos indivíduos (OLIVEIRA, 2004; REIS et al. 2005). Diante deste contexto, este estudo teve como objetivo identificar a relação entre o suporte social e organizacional percebido no trabalho e o comprometimento organizacional, considerando a percepção de professores da rede municipal de ensino.

Em relação ao suporte social no trabalho, observou-se que existem percepções semelhantes quanto aos tipos emocional e informacional do suporte social no trabalho e, por outro lado, uma menor valorização do suporte social instrumental. Enquanto o suporte social informacional diz respeito à crença de que a escola dispõe de uma rede de comunicações por meio da qual são veiculadas informações precisas e confiáveis, provendo informações importantes acerca de sua relação com a mesma; a percepção de suporte emocional refere-se à crença de que existem pessoas confiáveis, preocupadas umas com as outras, que se valorizam e se gostam (GOMIDE JUNIOR; GUIMARÃES; DAMÁSIO, 2008). Em relação ao contexto estudado, o apoio emocional possui um papel fundamental, uma vez que o contato com os colegas de trabalho faz com que se tornem uma importante fonte de apoio social emocional. Assim sendo, as escolas devem promover um ambiente escolar de incentivo ao desenvolvimento de relações positivas, as quais afetam positivamente a qualidade de vida e o bem-estar no trabalho (POMAKI et al., 2010; YEE; YEE, 2010).

Levando em consideração o suporte organizacional, que tem a função de satisfazer as necessidades emocionais, afiliação, estima e aprovação (RHOADES; EISENBERGER, 2002), os resultados deste estudo sinalizam para uma elevada percepção de suporte organizacional, o que indica que os professores percebem o comprometimento da escola com a sua satisfação no trabalho e o bem-estar. O resultado, desse modo, é extremamente positivo, na medida em que a elevada percepção de suporte organizacional pode suscitar comportamentos pró-ativos por parte dos indivíduos.

O comprometimento organizacional pode ser entendido como um importante vínculo psicológico, que une o indivíduo à organização, reduzindo a probabilidade deste desligar-se, sendo também considerado um preditor de atitudes e comportamentos que contribuem para a eficácia organizacional (GIFFORDS, 2009). Em relação aos professores pesquisados, os resultados indicam um elevado comprometimento normativo e afetivo e um baixo comprometimento instrumental.

A valorização do comprometimento normativo foi evidenciada por meio da maior valorização da base Obrigação pelo Desempenho. Visto desta forma, o comprometimento organizacional apresenta um caráter relacionado à obrigação em executar as tarefas, visando atingir resultados específicos para a organização, devido à internalização de pressões normativas, as quais são, de um modo geral, provenientes da cultura organizacional, por meio da qual a organização impõe ações e comportamentos aos indivíduos, a fim de envolvê-los em seus ideais (WIENER, 1982).

Estas pressões normativas, no caso da categoria docente, são provenientes do próprio ambiente institucional, tendo em vista que este acaba por gerar nos professores um sentimento de obrigação em responder às novas demandas pedagógicas e administrativas, provenientes principalmente de reformas educacionais, que se concretizam no cotidiano do seu trabalho. Considerando, principalmente, o resultado final do trabalho docente, ou seja, o processo de ensino-aprendizagem de seus alunos, o sentimento de obrigação pelo seu desempenho pode indicar o sentimento de possuir responsabilidades aquém do seu raio de atuação com os resultados dos seus alunos.

Por outro lado, a pesquisa sinalizou uma baixa valorização das bases relacionadas ao comprometimento instrumental (linha consistente de atividade, escassez de alternativas e falta de recompensas e oportunidades). A baixa valorização dessas bases pode apontar um fato positivo, uma vez que este não traz resultados relevantes para a organização (KARAKUS; ASLAN, 2009). Além disso, os funcionários comprometidos instrumentalmente estão interessados apenas na manutenção da condição de funcionários da organização, cumprindo tão-somente os requisitos mínimos aceitáveis para garantir a estabilidade no emprego (LUCHAK; GELLATLY, 2007).

Tendo em vista a relação entre o suporte social no trabalho e o comprometimento organizacional, os resultados demonstraram que o tipo emocional do suporte social apresenta alta correlação 
com as bases afiliativa e afetiva do comprometimento organizacional. Tais resultados remetem à compreensão de que, quando maior for a percepção de suporte destinado à satisfação de necessidades de ordem emocional, relacionadas a expressões de afeto, compreensão e cuidado (COHEN, 2004), maior será o desejo de permanecer na organização e de ser parte do grupo de trabalho, bem como a identificação do indivíduo tanto com os valores e os objetivos organizacionais.

Os resultados indicaram também que o suporte social relacionado às informações de que o indivíduo dispõe no ambiente de trabalho mostraram correlações elevadas com o comprometimento afetivo, demonstrando que a percepção de que as informações estão disponíveis na organização é correlata ao sentimento de identificação com a filosofia e os valores da mesma. Por outro lado, foi evidenciado que a percepção em relação ao apoio material disponível na organização apresenta relações fracas com as sete bases utilizadas para avaliar o comprometimento organizacional neste estudo.

Também se obtiveram resultados significativos no que tange às relações entre o suporte organizacional e o comprometimento organizacional, bem como entre esta variável e a percepção de suporte social no trabalho. Tendo em vista a relação com o comprometimento organizacional, a pesquisa apontou a existência de relações fortes entre o suporte organizacional e as bases afiliativa, obrigação em permanecer e afetiva. Nesse sentido, os resultados confirmaram a literatura em torno do tema (RHOADES; EISENBERGER, 2001).

Assim sendo, a percepção dos professores sobre a qualidade do tratamento recebido por parte da organização como retribuição ao esforço que despendido no trabalho (EISENBERGER et al. 1986) influencia no desenvolvimento do comprometimento afiliativo, afetivo, assim como no sentimento de que possuem obrigação em permanecer na escola. Por outro lado, o apoio organizacional não estabeleceu correlação relevante com a base linha consistente de atividade, escassez de alternativas e falta de recompensas e oportunidades, demonstrando que o comprometimento instrumental não se mostrou como um bom correlato da percepção de suporte organizacional.

Convém ainda ressaltar a relação entre suporte social no trabalho e suporte organizacional. Nesse aspecto, os resultados remetem ao entendimento de que a percepção de que a organização reconhece o esforço, oferece auxílio e apoio às necessidades socioemocionais dos seus professores (ALLEN et al., 2008) relaciona-se com a percepção acerca das informações disponíveis no ambiente organizacional e com o apoio emocional disponibilizado. Diante destas considerações, pode-se perceber que este estudo avançou na linha de entendimento acerca dos aspectos envolvidos nas relações de trabalho e que influenciam na decisão de permanecer como membro da organização, tendo em vista a realidade vivenciada por professores de escolas públicas municipais. Do ponto de vista das suas contribuições, o estudo fornece importantes implicações para o desenvolvimento de ações e práticas que visem a melhores condições de trabalho para os professores municipais.

Considerando a realidade experenciada por docentes municipais, os resultados obtidos neste estudo refletem questões relacionadas ao bem-estar no trabalho, bem como ao comprometimento organizacional. Tendo em vista a importância destes profissionais para o desenvolvimento da qualidade da educação no Brasil, tais aspectos são extremamente relevantes, uma vez que se inserem em debates relacionados à gestão pública, com enfase nas condições que podem estar relacionadas ao comprometimento de seus funcionários. Como fatores limitantes, pode-se citar o fato de que o estudo circunscreveu-se à coleta e à análise de dados quantitativos, bem como ao dado de que não foram investigadas outras esferas presentes no comprometimento dos professores, tais como a educação, os alunos, a comunidade escolar. Sugere-se que estudos futuros avancem nesta linha.

\section{REFERÊNCIAS}

ALLEN, M.; ARMSTRONG, D.; REID, M.; RIEMENSCHNEIDER, C. Factors impacting the perceived organizational support of IT employees. Information \& Management, v. 45, n. 8, p. 556-563, 2008.

ASELAGE, J.; EISENBERGER, R. Perceived organizational support and psychological contracts: A theoretical integration. Journal of Organizational Behavior, v. 24, n. 5, p. 491-509, 2003.

BECKER, T. Foci and bases of commitment: are they distinctions worth making? Academy of Management Journal, p. 232-244, 1992. 
BERTHELSEN, H.; HJALMERS, K.; SODERFELDT, B. Perceived social support in relation to work among Danish general dental practitioners in private practices. European Journal of Oral Sciences, v. 116, n. 2, p. 157-163, 2008.

BLAU, P. Exchange and power in social life. Transaction Publishers, 1986.

BRASIL. Ministério da Educação. Plano de Desenvolvimento da Educação: razões, princípios e programas. 2007. Disponível em: <http://portal.mec.gov.br/arquivos/pdf/ livromiolov4.pdf>. Acesso em: 06 de Janeiro de 2011.

BRASIL. Parâmetros Curriculares Nacionais: Ensino Fundamental. Brasília: MEC/SEF, 1997.

COBB, S. Social support as a moderator of life stress. Psychosomatic Medicine, v. 38, n. 5, p. 300314, 1976.

CODO, W. Educação: carinho e trabalho. Petrópolis: Vozes, 1999.

COHEN, S. Social relationships and health. American Psychologist, v. 59, p. 676-684, 2004.

DUARTE, S. G. Dicionário Brasileiro de Educação. Rio de Janeiro: Nobel, 1986.

EISENBERGER, R.; FASOLO, P.; DAVIS-LAMASTRO, V. Perceived Organizational Support and employee dilligence, commitment, and innovation. Journal of Applied Psychology, v. 75, n. 2, p. 51-59, 1990.

EISENBERGER, R.; HUNTINGTON, R.; HUTCHISON, S.; SOWA, D. Perceived Organizational Support. Journal of applied psychology, v. 71, n. 3, p. 500-507, 1986.

GIFFORDS, E. An examination of organizational commitment and professional commitment and the relationship to work environment, demographic and organizational factors. Journal of Social Work, v. 9, n. 4, p. 386, 2009

GOMIDE JR, S.; GUIMARÃES, L. C.; DAMÁSIO, L. F. Construção e Validação da Escala de Percepção de Suporte Social no Trabalho - EPSST. In: SIQUEIRA, M. M. M. (Ed.). Medidas de Comportamento Organizacional: Ferramentas de Diagnóstico e de Gestão. Porto Alegre: Artmed, 2008. p.286-292.

HAIR, J. F.; BABIN, B.; MONEY, A.; SAMOUEL, P. Análise multivariada de dados. 6. Porto Alegre: Bookman, 2009.

HOGAN, B.; LINDEN, W. ; NAJARIAN, B. Social support interventions Do they work? Clinical Psychology Review, v. 22, n. 3, p. 381-440, 2002.

JACKSON, L.; ROTHMANN, S.; VAN DE VIJVER, F. A model of work related well being for educators in South Africa. Stress and Health, v. 22, n. 4, p. 263-274, 2006.

JONES, R. J. Social Identity and Relational Demography in Workplace: A Quantitative Investigation of Ethinicity, Social Support, and Organizational Commitment. 2005. 226 f. Dissertation (Doctor of Education). George Washington University

KARAKUS, M.; ASLAN, B. Teachers' commitment focuses: a three-dimensioned view. Journal of Management Development, v. 28, n. 5, p. 425-438, 2009.

LAVELLE, J.; RUPP, D.; BROCKNER, J. Taking a Multifoci Approach to the Study of Justice, Social Exchange, and Citizenship Behavior: The Target Similarity Model†. Journal of Management, v. 33, n. 6, p. 841, 2007.

LUCHAK, A.; GELLATLY, I. A comparison of linear and nonlinear relations between organizational commitment and work outcomes. Journal of applied psychology, v. 92, n. 3, p. 786-793, 2007.

MEDEIROS, C.; ALBUQUERQUE, L.; SIQUEIRA, M.; MARQUES, G. Comprometimento organizacional: o estado da arte da pesquisa no Brasil. Revista de Administração Contemporânea, v. 7, p. 187-209, 2003.

MEDEIROS, C.; DE ALBUQUeRQUE, L.; MARQUES, G.; SIQUEIRA, M. Um estudo exploratório dos múltiplos componentes do comprometimento organizacional. Revista Eletrônica de Administração, , v. 43, n. 1, p. 1-22, 2005.

MEYER, J.; ALLEN, N. A three-component conceptualization of organizational commitment. Human resource management review, v. 1, n. 1, p. 61-89, 1991. 
OLIVEIRA, D. A reestruturação do trabalho docente: precarização e flexibilização. Educação \& Sociedade, v. 25, n. 89 , p. $1127-1144,2004$

PADOVAN, V. A. R. Antecedentes de bem-estar no trabalho: percepções de suportes e de justiça. 2005. 135 f. Dissertação (Mestrado em Psicologia). Universidade Metodista de São Paulo, São Bernardo do Campo.

PANACCIO, A.; VANDENBERGHE, C. Perceived organizational support, organizational commitment and psychological well-being: A longitudinal study. Journal of Vocational Behavior, 2009.

PAPPAS, T. K. A Multi-Method Approach Involving The Role of Social Suppor on Diverse Workforce Adjustment: The Case of Organizational Commitment. 2007. 112 f. Dissertation (Doctor of Philosophy in Psychology). Illinois Institute of Technology, Chicago.

PESTANA, M. H.; GAGEIRO, J. N. Análise de dados para ciências sociais: a complementaridade do SPSS. 3. Lisboa: Sílabo, 2003.

POMAKI, G.; DELONGIS, A.; FREY, D.; SHORT, K.; WOEHRLE, T. When the going gets tough: Direct, buffering and indirect effects of social support on turnover intention. Teaching and Teacher Education, $v$. 26, n. 2, p. 1340-1346, 2010.

REIS, E. J. F. B. ; ARAUJO, T. M.; CARVALHO, F. M. ; BARBALHO, L.; SILVA, M. O. Docência e Exaustão Emocional. Educação \& Sociedade, v. 27, n. 94, p. p.229-253, jan/abr., 2006.

REIS, E. J. F. B.; CARVALHO, F. M.; ARAÚJO, T. M.; PORTO, L. A., ;; NETO, A. M. S. Trabalho e distúrbios psíquicos em professores da rede municipal de Vitória da Conquista, Bahia, Brasil. Cad. Saúde Pública, v. 21, n. 5 , p. $1480-1490,2005$.

RHOADES, L.; EISENBERGER, R. Perceived organizational support: A review of the literature. Journal of applied psychology, v. 87, n. 4, p. 698-714, 2002.

RHOADES, L.; EISENBERGER, R.; ARMELI, S. Affective Commitment to the Organization: The Contribution of Perceived Organizational Support. Journal of applied psychology, v. 86, n. 5, p. 825-836, 2001.

RODRIGUEZ, M.; COHEN, S. Social support. Encyclopedia of Mental Health, v. 3, p. 535-544, 1998.

SIQUEIRA, M. M. M.; GOMIDE JUNIOR, S. Suporte no Trabalho. In: SIQUEIRA, M. M. M. (Ed.). Medidas de Comportamento Organizacional: Ferramentas de Diagnóstico e de Gestão. Porto Alegre: Artmed, 2008. p.283-286.

SIQUEIRA, M. M. M.; GOMIDE JUNIOR, S. Vínculos do indivíduo com o trabalho e com a organização. In: ZANELLI, J. C.; BORGES-ANDRADE, J. E. e BASTOS, A. V. B. (Ed.). Psicologia, organizações e trabalho no Brasil. Porto Alegre: Artmed, 2004. p.300-328.

SOMECH, A.; BOGLER, R. Antecedents and consequences of teacher organizational and professional commitment. Educational Administration Quarterly, v. 38, n. 4, p. 555, 2002.

VÄÄNÄNEN, A.; TOPPINEN-TANNER, S.; KALIMO, R.; MUTANEN, P.; VAHTERA, J.; PEIRÓ, J. Job characteristics, physical and psychological symptoms, and social support as antecedents of sickness absence among men and women in the private industrial sector. Social Science \& Medicine, v. 57, n. 5, p. 807-824, 2003.

VANDENBERGHE, C.; BENTEIN, K.; STINGLHAMBER, F. Affective commitment to the organization, supervisor, and work group: Antecedents and outcomes. Journal of Vocational Behavior, v. 64, n. 1, p. 47-71, 2004.

WAYNE, S.; SHORE, L.; BOMMER, W.; TETRICK, L. The role of fair treatment and rewards in perceptions of organizational support and leader-member exchange. Journal of applied psychology, v. 87, n. 3, p. 590-598, 2002.

WIENER, Y. Commitment in organizations: A normative view. The Academy of Management Review, v. 7, n. 3, p. 418-428, 1982.

WIESENFELD, B.; RAGHURAM, S.; GARUD, R. Organizational identification among virtual workers: The role of need for affiliation and perceived work-based social support. Journal of Management, v. $27, \mathrm{n}$. 2, p. 213, 2001. 
YEE, S. A. Enhancing positive work relationships and the school environment: an exploratory case study of teachers' emotions. New Zealand. 2010. 117 f. Thesis (Master in Psychology). Massey University, Palmerston North, New Zealand.

\section{NOTA}

1 "Currículo por atividades" é a forma de tratamento didático dos conteúdos curriculares nas quatro primeiras séries do ensino fundamental ( $1^{\mathrm{a}}$ a $4^{\mathrm{a}}$ série) em que predominam situações de experiências concretas, sendo, dessa forma, uma categoria curricular com ênfase nas experiências de aprendizagem obtidas nestas situações e onde o caráter lúdico é o fator determinante para a aprendizagem (DUARTE, 1986; BRASIL, 1997). 